\title{
MICROSTRUCTURE AND MAGNETIC PROPERTIES OF NdFeB SINTERED MAGNETS DIFFUSION-TREATED WITH Cu/Al MIXED DyCo ALLOY-POWDER
}

\begin{abstract}
We investigated the microstructural and magnetic property changes of DyCo, $\mathrm{Cu}+\mathrm{DyCo}$, and $\mathrm{Al}+\mathrm{DyCo}$ diffusion-treated $\mathrm{NdFeB}$ sintered magnets. The coercivity of all diffusion treated magnet was increased at $880^{\circ} \mathrm{C}$ of $1^{\text {st }}$ post annealing(PA), by 6.1 $\mathrm{kOe}$ in $\mathrm{Cu}$ and $7.0 \mathrm{kOe}$ in $\mathrm{Al}$ mixed DyCo coated magnets, whereas this increment was found to be relatively low (3.9 kOe) in the magnet coated with DyCo only. The diffusivity and diffusion depth of Dy were increased in those magnets which were treated with $\mathrm{Cu}$ or $\mathrm{Al}$ mixed DyCo mainly due to comparatively easy diffusion path provided by $\mathrm{Cu}$ and $\mathrm{Al}$ because of their solubility with $\mathrm{Nd}-$ rich grain boundary phase. The formation of $\mathrm{Cu} / \mathrm{Al}$-rich grain boundary phase might have enhanced the diffusivity of Dy-atoms. Moreover, relatively a large number of Dy atoms reached into the magnet and mostly segregated at the interface of $\mathrm{Nd}_{2} \mathrm{Fe}_{14} \mathrm{~B}$ and grain boundary phases covering $\mathrm{Nd}_{2} \mathrm{Fe}_{14} \mathrm{~B}$ grains so that the core-shell type structures were developed. The formation of highly anisotropic (Nd, Dy) ${ }_{2} \mathrm{Fe}_{14} \mathrm{~B}$ phase layer, which acted as the shell in the core-shell type structure so as to prevent the reverse domain movement, was the cause of enhancing the coercivity of diffusion treated NdFeB magnets. Segregation of cobalt in Nd-rich TJP followed by the formation of Co-rich phase was beneficial for the coercivity enhancement, resulting in the stabilization of the metastable c- $\mathrm{Nd}_{2} \mathrm{O}_{3}$ phase.

Keywords: Nd-Fe-B sintered magnet, grain boundary diffusion process, low melting-point elements, DyCo alloy-powder
\end{abstract} diffusion

\section{Introduction}

Grain boundary diffusion treatment has been proposed as a heavy rare-earth (HRE) elements saving method, where HRE atoms are allowed to diffuse via grain boundary [1,2]. However, the controlled diffusion phenomenon to achieve its optimum effect for the improvement of magnetic properties has still been a challenge. Developing the core-shell microstructure is known to be the most effective way to enhance the coercivity, and reduce the Dy content. The mechanism of magnetic reversal in the $\mathrm{NdFeB}$ sintered magnet is mainly due to the nucleation of reverse magnetic domains in the grain boundary area [3-5]. Therefore, targeting the Dy to the regions around the grain boundary could enhance coercivity, thereby minimizing the reduction in remanence. Many researchers have referred to this microstructure as the "core-shell microstructure" [6-13], which can be easily obtained by the grain boundary diffusion process (GBDP) [68] using HRE such as Dy. However, GBDP has a limitation of diffusion depth since NdFeB sintered body becomes fully dense during sintering process.

On the other hand, microstructural optimization by controlling diffusion behavior of HRE atoms with the aid of appropriate material is of great interest. For this, $\mathrm{Cu}$ and $\mathrm{Al}$ could be effective promoters of diffusion of HRE atoms like Dy by improving wettability of Nd-rich grain boundary phase. The solubility limit of $\mathrm{Cu}$ with $\mathrm{Nd}_{2} \mathrm{Fe}_{14} \mathrm{~B}$ phase is almost negligible, diffusion of $\mathrm{Cu}$ occurs only through grain boundaries whereas $\mathrm{Al}$ has the solubility to the $\mathrm{Nd}_{2} \mathrm{Fe}_{14} \mathrm{~B}$ phase $[3,4]$.

Cobalt in NdFeB sintered magnet is beneficial for the improvement of remanence and Curie temperature but the creation of planar anisotropy in main phase decreases the coercivity $[9,10]$. However, in real case, Co concentration is found to be higher in Nd-rich phase of $\mathrm{NdFeB}$ sintered magnets, which results in considerable microstructural change of Nd-rich phase. The low melting element like $\mathrm{Cu}$ increases the wettability and continuity of Nd-rich phase thereby increasing the coercivity [11].

In this work, we paid an effort to investigate the role of low melting point elements such as $\mathrm{Cu}$ and $\mathrm{Al}$ on Dy diffusion behavior and corresponding effect on magnetic and microstructural properties after being mixed with DyCo alloy-powder used for diffusion treatment. These elements could provide comparatively an easy path for Dy to diffuse via grain boundary into the interior of a magnet rather than in the case where only Dy-compounds were used for diffusion treatment. The coercivity of the diffu-

\footnotetext{
* DEPT. OF ADVANCED MATERIALS ENGINEERING, SUNMOON UNIVERSITY, ASAN, CHUNGNAM 336-708, KOREA

*** R\&D CENTER OF JAHWA ELECTRONICS CO. LTD, CHEONGWON 363-922, KOREA 
sion processed magnets which were treated with $\mathrm{Cu}$ or $\mathrm{Al}$ mixed Dy-source was improved by increasing diffusivity of Dy without much deterioration of remanence and energy product.

\section{Experimental}

Magnetic powder having average particle size of $3 \mu \mathrm{m}$ with the composition of $\mathrm{Nd}_{29.00} \mathrm{Dy}_{3.00} \mathrm{Fe}_{\mathrm{Bal}} . \mathrm{B}_{0.97} \mathrm{M}_{2.39}$ (wt.\%, $\mathrm{M}=\mathrm{Cu}$, $\mathrm{Al}, \mathrm{Co}$ and $\mathrm{Nb}$ ) was taken in this study for the magnet preparation. Also, DyCo alloy-powder of average particle size $152 \mu \mathrm{m}$ was chosen as the Dy-source. The magnet samples were prepared through the powder metallurgical root and sintered at $1060^{\circ} \mathrm{C}$ for 4 hours. The sintered bulk magnet samples were cut into pieces of dimension $12.5 \mathrm{~mm} \times 12.5 \mathrm{~mm} \times 5 \mathrm{~mm}$ and were polished to remove the oxidized surface layer. Further, the polished samples were dipped in the solution prepared from the powders of $\operatorname{DyCo}(1.0 \mathrm{~g}), \mathrm{Cu}$ or $\mathrm{Al}(0.2 \mathrm{~g})$, and absolute ethanol(1 g). Three kinds of solutions; DyCo, $\mathrm{Cu}+\mathrm{DyCo}$, and $\mathrm{Al}+$ DyCo were prepared as the Dy supplier for diffusion treatment. Ultrasonic vibration was provided to make uniform coating layer of the Dysource on the magnet surface. In a while, those Dy-source coated samples were annealed in three stages; $1^{\text {st }}$ stage annealing was performed at $880^{\circ} \mathrm{C}$ for 8 hours, and the $2^{\text {nd }}$ the $3^{\text {rd }}$ stage at $530^{\circ} \mathrm{C}$ and $500^{\circ} \mathrm{C}$ for 2 hours each in vacuum $\left(\sim 10^{-5}\right.$ Torr $)$. Magnetic properties of the magnet samples were measured using a B-H loop tracer (Magnet-Physik Permagraph C-300). Microstructural investigation was carried out using a scanning electron microscopy (SEM, JXA-8500F) and High Resolution Transmission Electron Microscopy (HRTEM, JEOL JEM 2100F).

\section{Results and discussion}

Fig. 1 shows a comparison of the coercivity with three kinds of Dy-sources; DyCo only, $\mathrm{Cu}+$ DyCo and $\mathrm{Al}+$ DyCo. The coercivity of all diffusion-treated magnets was increased at $880^{\circ} \mathrm{C}$ of heat treatment, the coercivity of $\mathrm{Cu}$ dipped magnet increased by $6.1 \mathrm{kOe}$ and that of $\mathrm{Al}$ dipped magnet increased by $7.0 \mathrm{kOe}$. The increment of coericivity was found to be relatively low $(3.9 \mathrm{kOe})$ in the magnet coated with DyCo only. We observed that both $\mathrm{Cu}$ and $\mathrm{Al}$ had almost similar effect on coercivity improvement particularly in the heat treatment temperature. Our previous result showed that there was critical changes in the microstructure of Nd-rich triple junction phase (TJP) and grain boundary phase (GBP).

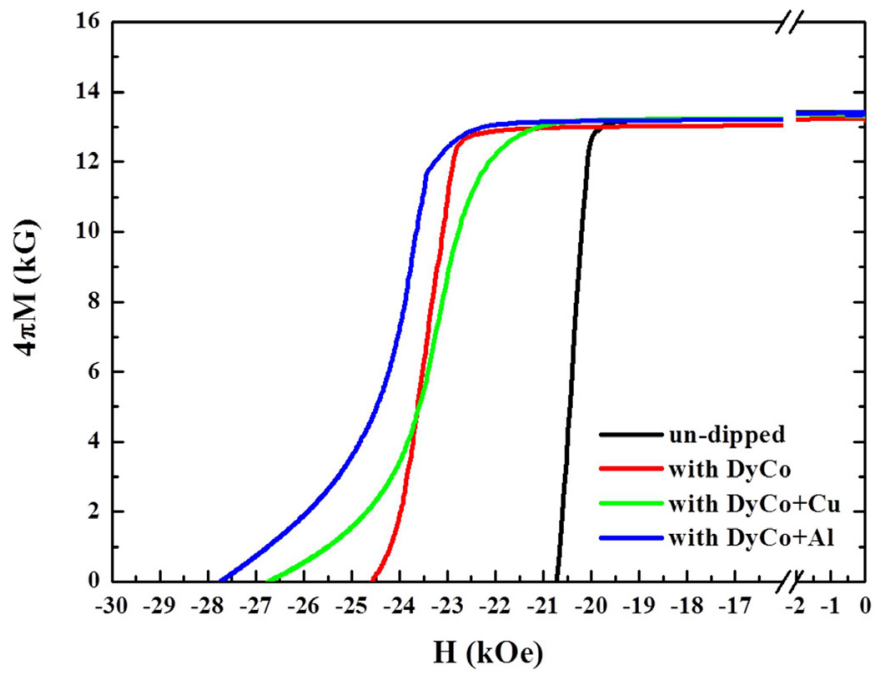

Fig. 1. Demagnetization curves of DyCo, $\mathrm{Cu}+\mathrm{DyCo}$ and $\mathrm{Al}+\mathrm{DyCo}$ dipped magnets

Fig. 2 shows the cross-sectional EPMA mapping images of (a) DyCo only, (b) DyCo $+\mathrm{Cu}$, and (c) DyCo+Al dipped magnets with $1^{\text {st }} \mathrm{PA}$ at $880^{\circ} \mathrm{C}$. As shown in Fig. 2b, Dy diffusion depth was increased as compared with the magnet treated with DyCo only (from $90 \mu \mathrm{m}$ to $450 \mu \mathrm{m}$ ). A Nd-rich core-shell type structure was formed almost at the surface region. This indicates that Dy diffused into the main phase. The $\mathrm{Cu}$ was segregated at $\mathrm{Nd}$-rich triple junction phase because $\mathrm{Cu}$ has poor solubility

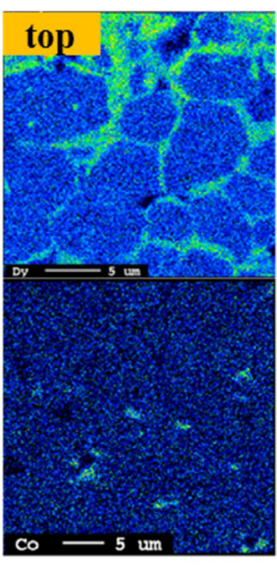

(a)

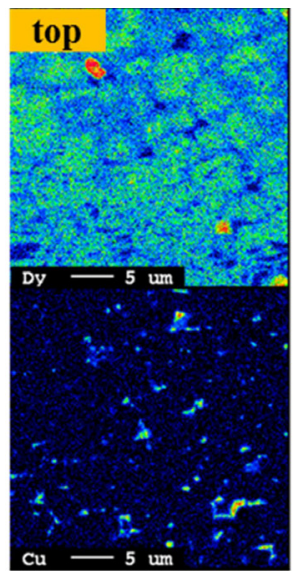

(b)

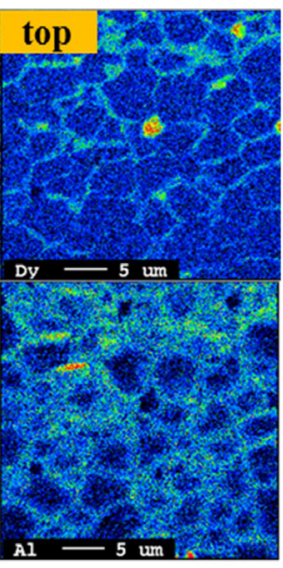

(c)

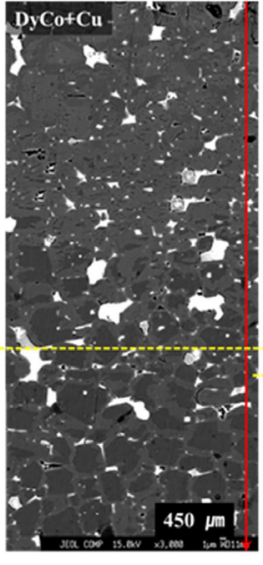

(d)

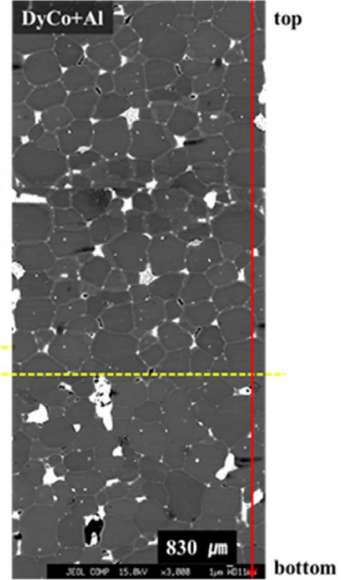

Fig. 2. Cross-sectional EPMA images of the surface area of (a) DyCo, (b) $\mathrm{Cu}+\mathrm{DyCo}$, and (c) $\mathrm{Al}+\mathrm{DyCo}$ dipped magnets. The formation depth of core-shell type grains due to the Cu-driven and Al-driven Dy source is shown in (d) 

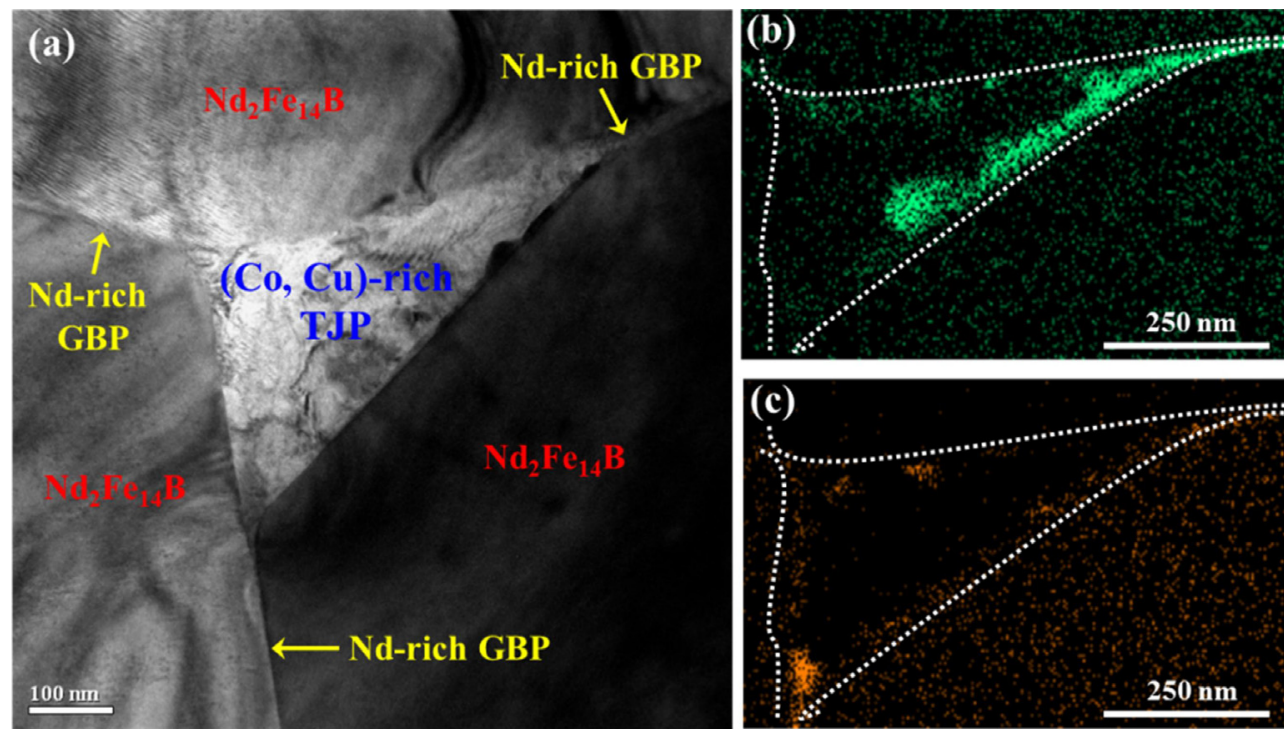

Fig. 3. (a) The bright field micrograph, (b) EDX mapping of $\mathrm{Cu}$ at Nd-rich TJP, and (c) EDX mapping of Co at Nd-rich TJP of the DyCo dipped magnet

with $\mathrm{Nd}_{2} \mathrm{Fe}_{14} \mathrm{~B}$ phase. In case of $\mathrm{Al}$ mixed DyCo treated magnet (Fig. 2c), it was observed that the Dy diffusion depth was considerably increased to $\sim 830 \mu \mathrm{m}$. Al was distributed in grain boundary phases and outer area of the main phases as a result of the fact that $\mathrm{Al}$ was soluble in the main phase. The results from these observation indicate different diffusion behavior of $\mathrm{Cu}$ and $\mathrm{Al}$ on the $\mathrm{NdFeB}$ sintered magnet. Owing to the improvement in distribution of Dy, and increased diffusion depth of the Dy atoms, the coercivity was enhanced by increasing the fraction of $\mathrm{Al}$ added during the GBDP.

Fig. 3(a) shows the TEM bright field image of the two-step annealed one, and (b) and (c) shows the EDX images of $\mathrm{Cu}$ and $\mathrm{Co}$ distribution in $(\mathrm{Co}, \mathrm{Cu})$-rich TJP, respectively. In general, Nd-rich TJP is composed of Nd-Co-Cu-O. The EDX mapping shown in Fig. 3 revealed that $\mathrm{Cu}$ and $\mathrm{Co}$ are not mixed perfectly throughout the TJP but separated to form $\mathrm{Cu}$-rich and $\mathrm{Co}$-rich region with approximate composition of $\mathrm{Nd}_{32.5} \mathrm{Co}_{2.6} \mathrm{Cu}_{30.2} \mathrm{O}_{34.8}$ and $\mathrm{Nd}_{32.9} \mathrm{Co}_{39.4} \mathrm{Cu}_{12.7} \mathrm{O}_{13.7}$ (in at. \%), respectively. On the other hand, the $\mathrm{Cu}$ and $\mathrm{Co}$ poor region (dark contrast in TJP) has the composition of $\mathrm{Nd}_{44.3} \mathrm{Co}_{0.25} \mathrm{Cu}_{0.43} \mathrm{O}_{51.2}$. In case of Co and $\mathrm{Nd}$, the eutectic decomposition reaction can occur at $\sim 630^{\circ} \mathrm{C}$. Therefore, $\mathrm{L} \leftrightarrow \mathrm{Nd}+\mathrm{Nd}_{3}$ Co eutectic reaction can occur during $1^{\text {st }}$ PSA. Because of this eutectic decomposition, the TJP has Co-rich region as well as Co-poor region. In case of $\mathrm{Cu}$ and $\mathrm{Nd}$, however, the eutectic decomposition occurs at $\sim 500^{\circ} \mathrm{C}$, thus there is no chance to form $\mathrm{Cu}$-rich phase from eutectic reaction during $2^{\text {nd }}$ PSA. Also, Cu has no solubility to the main magnetic phase at $2^{\text {nd }}$ PSA temperature and $\mathrm{Cu}$ can move towards the Co-poor region resulting in the formation of $\mathrm{Cu}$-rich phase [13].

Fig. 4 shows TEM bright field and SADP images of Nd-rich TJP in the $\mathrm{DyF}_{3}$ dipped magnet $(\mathrm{a}, \mathrm{c})$ and DyCo source coated magnet $(b, d)$. The crystal structure analysis revealed that the DyCo coated magnet was c- $\mathrm{Nd}_{2} \mathrm{O}_{3}$ but the Dy Compound coated magnet was h- $\mathrm{Nd}_{2} \mathrm{O}_{3}$ phase. $\mathrm{c}-\mathrm{Nd}_{2} \mathrm{O}_{3}$ phase was stabilized when $\mathrm{Co}, \mathrm{Cu}$ segregation was more than 30 at. \%, hence increasing the coercivity by reducing the interfacial lattice mismatch [13]. The formation of stable $\mathrm{c}-\mathrm{Nd}_{2} \mathrm{O}_{3}$ phase in TJP, although Co segregated in the TJP, seemed to be the reason of the coercivity enhancement in GBDP.
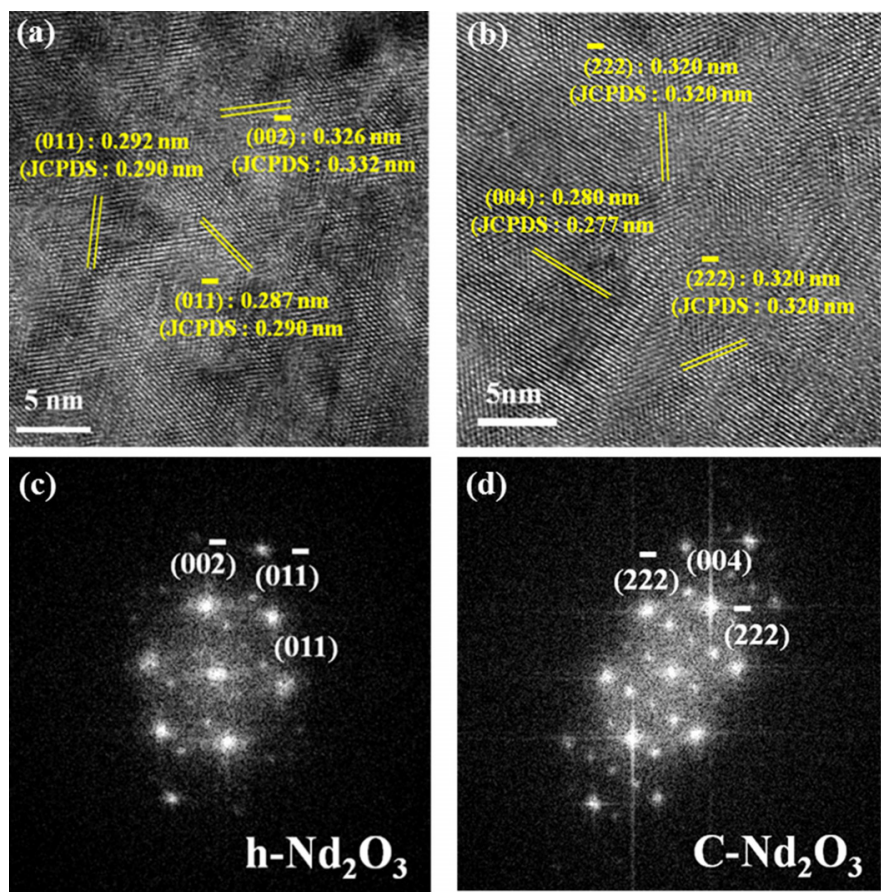

Fig. 4. HR-TEM micrograph and corresponding SADP images of (a), (c) $\mathrm{DyF}_{3}$ dipped magnet and (b), (d) DyCo dipped magnets

\section{Conclusions}

The magnetic and microstructure characteristics of the $\mathrm{NdFeB}$ sintered magnet dipped in DyCo, $\mathrm{Cu}+$ DyCo and $\mathrm{Al}+$ DyCo solutions were investigated. The coercivity of the $\mathrm{Al}+$ DyCo dipped magnet was higher than those of the $\mathrm{Cu}+$ DyCo 
dipped magnet and the magnet dipped in DyCo only, even though they all formed core-shell type structures. $\mathrm{Cu}$ and $\mathrm{Al}$ acted as the carriers of Dy atoms so that relatively large number of Dy atoms diffused into the magnet's interior from the Dy-source coated surface. The $\mathrm{Cu} / \mathrm{Al}$-rich grain boundary phase might have enhanced the diffusivity of Dy atoms. Large number of Dy atoms reached into the magnet and mostly segregated at the interface of $\mathrm{Nd}_{2} \mathrm{Fe}_{14} \mathrm{~B}$ and grain boundary phases covering $\mathrm{Nd}_{2} \mathrm{Fe}_{14} \mathrm{~B}$ grains to form core-shell type structures. The formation of highly anisotropic ( $\mathrm{Nd}, \mathrm{Dy})_{2} \mathrm{Fe}_{14} \mathrm{~B}$ phase layer due to Dy diffusion is responsible to screen the reverse domain movement by forming shells in the core-shell type structures. This was the main cause of the enhanced coercivity of diffusion treated NdFeB magnets.

\section{Acknowledgments}

This work is supported by the Strategic Core Material Technology Development Program (No10043780) funded by the ministry of Trade, Industry and Energy (Korea)

\section{REFERENCES}

[1] K. Hirota, H. Nakamura, T. Minowa, M. Hoshima, IEEE Trans. Magn. 42, 2909-2911 (2006).

[2] H. Sepehri-Amin, T. Ohkubo, K. Hono, J. Appl. Phys. 107, 09A745 (2010).
[3] K.H.J. Buschow, J. Mater. Sci. Res. 1, 1-64 (1986)

[4] J. Fidler, J. Bernardi, J. Appl. Phys. 70, 6456-6458 (1991).

[5] D.S. Li, S. Suzuki, T. Kawasaki, K. Machida, Jpn, J. Appl. Phys. 47, 7876-7878 (2008).

[6] K. Hirota, H. Nakamura, T. Minowa, M. Honshima, IEEE Trans. Magn. 41, 2909-2911 (2006).

[7] D.S. Li, M. Nishimoto, S. Suzuki, K. Nishiyama, M. Itoh, K. Machida, 2009 IOP Conf. Ser.: Mater. Sci. Eng. 1, 012020 (2009).

[8] M. Komuro, Y. Satsu, H. Suzuki, IEEE Trans. Magn. 46, 38313833 (2010).

[9] B.E. Davies, R.S. Mottram, I.R. Harris, J. Mater. Chem. Phys. 64, 272-281 (2001)

[10] A. Kowalczyk, A. Wrzeciono, J. Magn. Magn. Mater. 74, 260 (1988).

[11] W.F. Li, T. Ohkubo, T. Akiya, H. Kato, K. Hono, J. Mater. Res. 24, 413 (2009).

[12] S. Hirosawa, Y. Matsuura, H. Yamamoto, S. Fujimura, M. Sagawa, H. Yamauchi, J. Appl. Phys. 59, 873-879 (1986).

[13] T.N. Rezukhina, T.F. Sisoeva, J. Chem. Thermodynamics. 11, 1095-1099 ( 1979).

[14] J.A. Kerr, CRC Handbook of Chemistry and Physics 1999-2000 : A Ready-Reference Book of Chemical and Physical Data 81 st es., USA (2000).

[15] H. NaKamura, K. Hirota, M. Shimao, T. Minowa, M. Honshima, IEEE. Tran. Magn. 41, 3844-3946 (2005).

[16] D.W. Park, T.H. Kim, S.R. Lee, D.H. Kim, T.S. Jang, J. Appl. Phys., 107, 09A737-1-09A737-3 (2010). 